\title{
ISOLATION, CHARACTERIZATION, AND ANTIMICROBIAL ACTIVITY OF ACTINOMYCETES ISOLATED FROM GARDEN SOIL
}

\author{
Jacintha Jasmine Doss ${ }^{*}$, Anita Rosemarie Joseph Singh ${ }^{*}$ \\ * Women's Christian College, PG and Research Department of Biotechnology, Affiliated to the University of \\ Madras, Chennai, Tamil Nadu, India
}

corresponding author: Anita Rosemarie Joseph Singh, e-mail: anjo_64@ yahoo.com

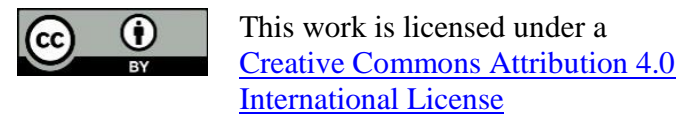

\author{
Original scientific paper \\ Received: February $24^{\text {th }}$, 2020 \\ Accepted: May $7^{\text {th }}, 2020$ \\ HAE-1939 \\ https://doi.org/10.33765/thate.11.1.1
}

\begin{abstract}
Five different strains of Actinomycetes were isolated from rhizosphere soil sample taken from Tulsi gardens of Kayathar, Tuticorin District. Heat treated Tulsi growing rhizosphere soil samples (Kayathar, Tuticorin District) were subjected to serial dilution and plated on starch casein medium, incubated at $37{ }^{\circ} \mathrm{C}$ for 7 - 14 days. The isolated strains were subjected to morphological, biochemical and cultural characterisation to study their spore morphology, asexual reproductive spores, substrate mycelial growth and enzyme degradation. Tests were performed as per International Streptomyces Project (ISP). Morphological and cultural characteristics showed that the strains AJ1, AJ2, AJ3, AJ4 and AJ5 belonged to the genus Actinomycete. The cultures showed substrate and aerial mycelial growth and also soluble pigments. Based on their morphology the isolates were subjected to antimicrobial activity against pathogens. Antimicrobial activity was performed against seven clinical isolates. AJ1 was found to show maximum activity against Klebsiella, S.typhi and Enterobacter whereas AJ5 was found to show inhibitory activity against Klebsiella.
\end{abstract}

Keywords: Actinomycetes, morphology, characterization, antimicrobial activity

\section{INTRODUCTION}

Actinomycetes are intermediary microorganisms both in structure and function between bacteria and fungi and are found to be heterotrophic in nature. Actinomycetes flourish on biodegradable organic matter and inflate in aerobic soils. Actinomycetes are branched filamentous organisms capable of decomposing synthetic non-biodegradable compounds, namely cellulose. These organisms are responsible for the earthy odour produced after rains or while ploughing amorphous soil [1]. The word Actinomycetes is not under the classification in a hierarchical system also called "thread or ray bacteria". Actinomycetes are capable of decaying organic materials such as chitin, which forms the exoskeleton of insects. Actinomycetes generally have a high $\mathrm{G}+\mathrm{C}$ base pair 
composition with a thick peptidoglycan layer which indicates gram positive, and form thread-like structures [2].

Actinomycetes produce extracellular enzymes by breaking down organic matter, rebuilding them and by utilizing the macromolecules from dead plant and animal residues and also prevent the growth of plant pathogens. They play a vital role in the absorption and release of nutrients in soil, fix up nitrogen by controlling the soil environments and in the breakdown of hydrocarbons in the polluted soils. Adding to this, they also make the nutrients and minerals available, support plant growth promoters by enriching plant and soil health thereby improving metabolites production. Furthermore, they do not pollute the environment, but in turn perk up compost piles, promote humus formation as well as mediate the degradation of plant residues, namely cellulose by associating with other soil organisms, which help to maintain the soil biota [3]. Actinomycetes are diverse and farstretched in soil, compost etc. The number of cells ranges from 10,000 to $10^{8}$ per gram of soil. Acidic conditions ( $\mathrm{pH}$ range from 6.5 to 8.0) and water saturated soil area makes the Actinomycetes highly sensitive. Actinomycete is densely populated in soil surface layer and decreases with depth [4]. The population of Actinomycetes population increases even up to horizon ' $\mathrm{C}$ ' where no humus accumulation takes place. They can grow in a moderate temperature range between $20-45{ }^{\circ} \mathrm{C}$ and are aerobic organisms utilizing sugars for their survival and reproduction. Actinomycetes are mostly present in fertile soil and are thermophilic organisms thriving at temperatures between 41 and $122{ }^{\circ} \mathrm{C}$ (e.g. Thermoactinomycetes, Streptomyces) [5].

Actinomycetes are categorized into seven families, namely Streptomycetaceae, Nocardia, Actinoplanaceae, Mycobacteriaceae, Frankiaceae and Actinomycetaceae.

Streptomyces denote for $70 \%$ of being the most common genera of Actinomycetes population including Bifidobacterium,
Arthrobacter,

Propionibacterium, Actinoplanes, Micromonospora and Streptosporangium as well.

This article highlights the isolation of novel Actinomycetes from rhizosphere soil sample, followed by the study of its characterization and antimicrobial activity to find new bioactive metabolites against multidrug resistant pathogens.

\section{EXPERIMENTAL}

\section{Sampling area}

Samples from rhizosphere soil were collected from the Garden located $5 \mathrm{~km}$ from East direction of Kayathar, Tuticorin District, Tamil Nadu, located at latitude of $8.62035 \mathrm{~N}$ and a longitude of $77.97732 \mathrm{E}$. The gardens total surface area comprises of $0.0202343 \mathrm{~km}^{2}$ with an average of $78 \mathrm{~m}$ elevation above sea level. Approval letter from the garden, since it is a private garden, and is not a corporation owned or a Government property, cannot be obtained.

\section{Sample collection}

Soil samples collected from the garden of Kayathar, Tuticorin District were stored in sterile containers with space provided for air to pass through. The samples were transferred to sterile containers using a sterile spatula. All samples were labelled and transported to PG and Research Department of Biotechnology, Women's Christian College, and maintained at $4{ }^{\circ} \mathrm{C}$ for future studies.

\section{Pre-treatment of samples}

Soil samples were air dried for 2 hours and subjected to pre-treatment by heating at $75{ }^{\circ} \mathrm{C}$ for 3 minutes, which kills most of the unwanted bacteria and facilitates the isolation of Actinomycetes as well as any other new Streptomyces strains [6]. 


\section{Isolation of Actinomycetes}

$1 \mathrm{~g}$ of heat treated soil sample was weighed and suspended in $99 \mathrm{ml}$ of sterile distilled water to make up the stock solution. $1 \mathrm{ml}$ of the stock solution was pipetted out into test tube containing $9 \mathrm{ml}$ of sterile distilled water which makes $10^{-1}$ dilution. $1 \mathrm{ml}$ of the serially diluted solution from $10^{-1}$ dilution was pipetted out into the first test tube containing $9 \mathrm{ml}$ of sterile distilled water which makes $10^{-2}$ dilution, making up to $10^{-6}$ dilutions [7]. Isolation of Actinomycetes was carried out by taking $100 \mu 1$ of the diluted solution from $10^{-4}$, $10^{-5}$ and $10^{-6}$ dilutions and spreading onto starch casein agar medium suspended with rifampicin $(30 \mu \mathrm{g} / \mathrm{ml})$, actidione $(80 \mu \mathrm{g} / \mathrm{ml})$ and nystatin $(50 \mu \mathrm{g} / \mathrm{ml})$ respectively. This was done in order to avoid bacterial and fungal growth followed by incubation at $37^{\circ} \mathrm{C}$ in the incubator for 7 - 14 days [8] (Figure 1).
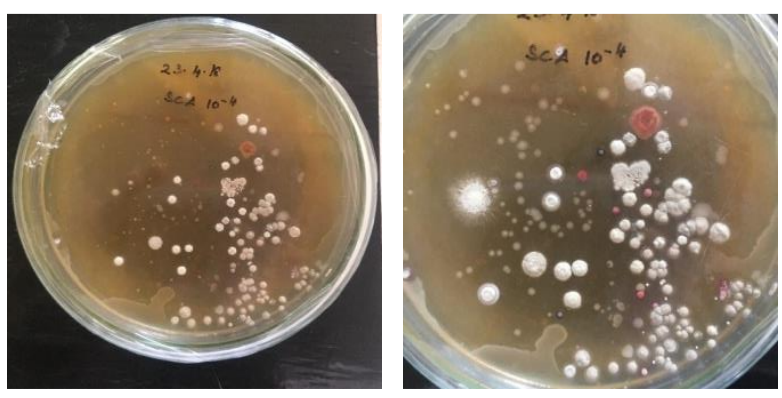

Figure 1. Isolation of Actinomycetes isolates

\section{Purification of Actinomycetes isolates}

Single colonies of Actinomycetes isolates were sub cultured from a mixture of colonies by picking them with a sterile loop and streaking them on Actinomycetes isolation agar medium specific for its growth. Actinomycetes colonies found to be contaminated with fungi were again transferred to another sterile media and sub cultured to get pure colonies. They were plated on Actinomycetes isolation agar and stored for further studies (Figure 2).

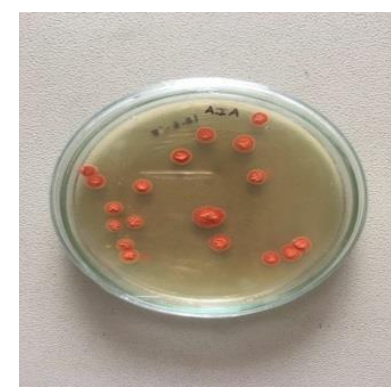

AJ1

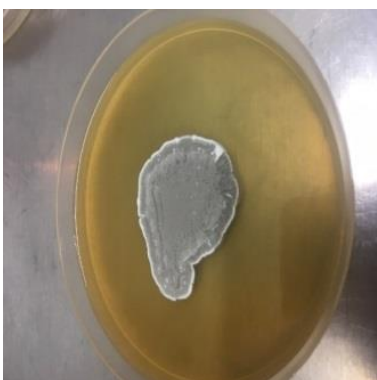

$\mathrm{AJ} 3$

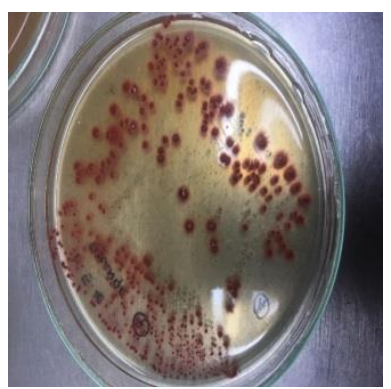

$\mathrm{AJ} 2$

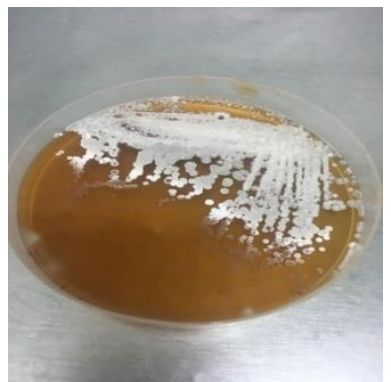

AJ4

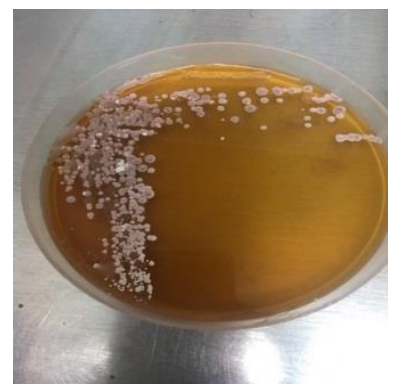

AJ5

Figure 2. Purification of Actinomycetes isolates (AJ1, AJ2, AJ3, AJ4 and AJ5)

\section{Morphological characterisation of Actinomycetes}

Macroscopically, the isolates were categorised by their shape, size, and colour of the colonies.

\section{Microscopic examination of Actinomycetes}

\section{a) Lactophenol cotton blue staining (LPCB)}

This technique stains and preserves the structure of the Actinomycetes hence it can be observed under the microscope. A drop of 70 $\%$ ethanol was placed on a clean microscopic glass slide. The specimens were immersed in the drop of alcohol. One or at most two drops of LPCB were added before the alcohol dried 
out. The coverslip was held between the index finger and thumb, one edge of the drop of mount was touched with the coverslip edge and lowered gently to avoid air bubbles. This preparation was initially examined by using low power objective. The more detailed examination of spores and other structures was carried out by switching to high power (40X).

\section{b) Gram staining}

This technique helps to differentiate and identify if the isolate is gram positive or gram negative. With a sterile cooled loop, a drop of sterile water or saline solution was placed on the slide. The loop was heat sterilized, cooled and a very small sample of the colony was taken and gently stirred into the drop of water/saline on the slide to create an emulsion. The smear was air dried. The air-dried slide was showed in between the flames of a Bunsen burner to smear-side up. The smear was then flooded with gentian violet stain and left for 1 min. The smeared slide was washed under running tap water. The smear was then gently flooded with grams iodine and allowed to stand for $1 \mathrm{~min}$. The smeared slide was rinsed under tap water and submerged with grams decolouriser and left for 30 seconds. The slide was again rinsed under tap water and flooded finally with safranin and allowed to stand for 1 min. The slide was again rinsed under running tap water and blot dried with a blotting paper. The slide was observed under a research microscope model 3000X. The culture retained the violet colour and was indicated as gram positive organism [9].

\section{c) Coverslip technique}

Coverslip culture is an important tool for studying the micromorphology of filamentous Actinomycetes under undisturbed condition. Spore chain morphology, aerial mycelium, shape and number of spores in spore chain etc. can be studied. The isolates were grown and maintained in Actinomycetes isolation agar and inoculated on Bennett's agar medium for enhanced growth. Coverslip was wiped with ethanol and inserted into the Petri plate at an inclined angle of $45^{\circ}$ followed by incubation at
$37{ }^{\circ} \mathrm{C}$. The plates were observed under high power and oil immersion microscope on the $7^{\text {th }}, 14^{\text {th }}$ and $21^{\text {st }}$ day. Morphology of aerial mycelium, substrate mycelium, arrangement of sporogenous hyphae, and their morphology were recorded according to ISP $[10,11]$.

\section{Cultural characterization of Actinomycetes}

Characterisation of Actinomycetes refers to the study of the shape, structure, and formation of aerial mycelium, pigment production, substrate mycelial growth when grown in different kinds of culture media. After an incubation period of 14 days at $28{ }^{\circ} \mathrm{C}$, the cultures were observed for any morphological growth according to the methods suggested in the International Streptomyces Project (ISP). Presence of any diffusible pigments, aerial and substrate mycelial hyphae was determined as well [12]. The standard culture media used were: ISP medium 2 (yeast-malt extract agar), ISP medium 3 (oatmeal agar), ISP medium 4 (inorganic salt starch casein agar), ISP medium 5 (glycerol asparagine agar) and ISP medium 7 (tyrosine agar).

\section{Inoculation of plates for morphological studies}

$3-5 \mathrm{ml}$ of sterile distilled water was taken in test tubes. Wired loop was sterilized by heating it red hot in flame and cooled under aseptic conditions, using which a loopful of culture was transferred into test tubes containing sterile distilled water until a turbid suspension was obtained. About $0.05 \mathrm{ml}$ of the inoculum was placed on to the agar surface near one edge of the Petri dish which served as a pool of inoculum. A flame-sterilized wire loop was used and 5 equally spaced streaks across the plate were made. The plates were incubated in the dark at $25-28{ }^{\circ} \mathrm{C}$ and observed after 7, 14 and 21 days.

\section{Biochemical characterization of Actinomycetes}

Biochemical characterization of the individual isolate is of the utmost importance to 
understand the basic physiology of the Actinomycete isolates. The biochemical tests for characterisation were done according to Cappuccino [13]. Biochemical tests were carried out for the identification of potent cultural isolates, namely starch, casein, and gelatin hydrolysis, triple sugar iron test, carbohydrate fermentation, citrate fermentation test, urease test, catalase test, hydrogen sulphide, methyl red-vogues proskauer test etc.

\section{Antimicrobial activity}

Antimicrobial activity of $\mathrm{AJ} 1, \mathrm{AJ} 2, \mathrm{AJ} 3, \mathrm{AJ} 4$ and AJ5 was performed against five test organisms namely Klebsiella, S.typhi, S.mutans, Enterobacter and E.coli. The isolates $\mathrm{AJ} 1, \mathrm{AJ} 2, \mathrm{AJ} 3, \mathrm{AJ} 4$ and $\mathrm{AJ} 5$ were grown on starch casein agar medium for 7 days at $37{ }^{\circ} \mathrm{C}$. Test organisms were swabbed on nutrient agar plates using sterile cotton swabs. Agar discs containing the isolates AJ1, $\mathrm{AJ} 2, \mathrm{AJ} 3, \mathrm{AJ} 4$ and $\mathrm{AJ} 5$ were placed on the surface of the test organisms swabbed agar plates and incubated for 24 hours. The measured activity denotes the diameter of inhibition in millimetres.

\section{RESULTS}

Five Actinomycetes isolates $\mathrm{AJ} 1, \mathrm{AJ} 2, \mathrm{AJ} 3$, AJ4 and AJ5 were isolated from pre-treated soil samples collected from Tulsi gardens of Kayathar, Tuticorin District and were subjected to purification by streak plate technique (Figure 2).

Cultural and physiological characteristics of the cultural isolates were determined based on the methods described by the International Streptomyces Project [14]. For morphological characteristics, the presence of aerial mycelium, spore mass colour, distinctive reverse colony colour, diffusible pigment, and sporophore and spore chain morphology were recorded after 10 days of incubation on ISP-2 medium.
The isolates AJ1, AJ2, AJ3, AJ4 and AJ5 were aerobic and found to be gram positive. The slides showed aerial mycelium with sporangium. Isolate AJ1 showed true mycelial structures with filamentous non septate hyphae and extensive branching. Spore bearing hyphae falls under flexibillis structure. AJ2 isolate showed pseudo mycelium with filamentous septate branching. Spore bearing hyphae falls under retinaculum open loops. Isolate AJ3 showed true mycelium with nonseptate hyphae and extensive branching. Spore bearing hyphae falls under biverticullus no spirals. The isolate AJ4 showed simple true mycelium with non-septate non-sporing hyphae. The isolate AJ5 showed aerial mycelium with extensive branching which had true mycelium and non-septate hyphae. Thermophilic genera and species were first characterized based on the colour of aerial mycelium, the formation of diffusible pigments and the mode of spore formation allowed the first characterization [15]. The isolates showed short and long chains mycelium. They were spore bearing and were found to be single with smooth conidia. Spore silhouettes were smooth for AJ1, AJ4 and AJ5, warty for AJ2 and hairy for AJ3 (Figure 3).

The five isolates AJ1, AJ2, AJ3, AJ4 and AJ5 were subjected to coverslip culture technique which is shown in Figure 4. The aerial mycelium, substrate mycelium, arrangement of sporogenous hyphae, their morphology (straight, flexuous, spiral shaped) were recorded according to International Streptomyces Project (ISP). This study revealed four types of spore chain morphology.

The five isolates were grown on different media to study the aerial spore mass appearance, reverse colony appearance and their shape.

The aerial mycelium produced a range of aerial spore mass colours, reverse colony and pigments. The mycelium that grows on the surface of the medium and spore mass were orange (AJ1), pink (AJ2), grey (AJ3), white (AJ4) and baby pink (AJ5) in colour. The 
colonies appeared leathery, powdery and velvety (AJ1, AJ3, AJ4, AJ5) as aerial spores developed. The isolate $\mathrm{AJ} 2$ was watery but didn't produce any aerial mycelium (Figure 5).

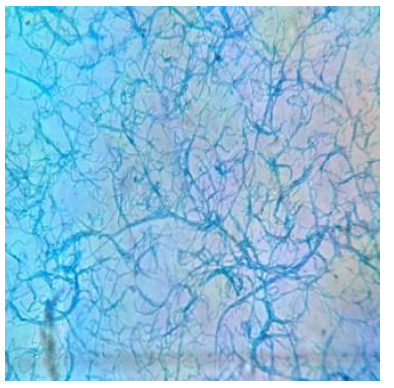

AJ1

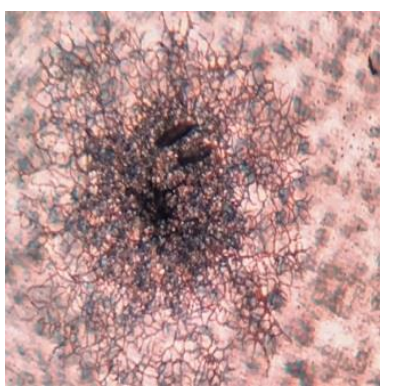

$\mathrm{AJ} 3$

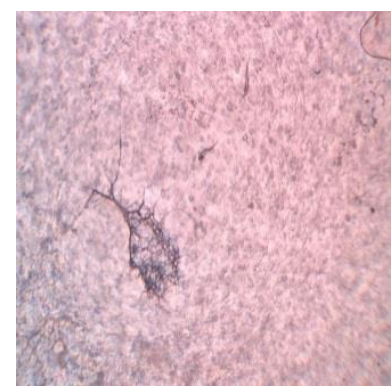

AJ5

Figure 3. Lactophenol cotton blue stain of the Actinomycetes isolates AJ1, AJ2, AJ3, AJ4 and AJ5

Although the appearance of the colonies on the surface looked the same, they appeared different when observed from the reverse side. This showed the difference in substrate hyphae. The colony reverse isolates were orange (AJ1), dark pink (AJ2), grey (AJ3), white (AJ4) and light pink (AJ5). This formed the basis for colony differentiation (Figure 6).

The colonies showed concentric circles on growth, with matte and spiky finish in the centre and sharp edges at the ends of the colony (Figure 7, Table 1).

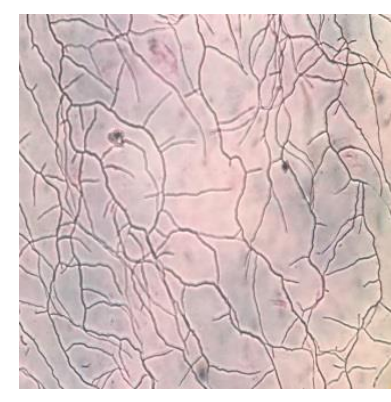

AJ1

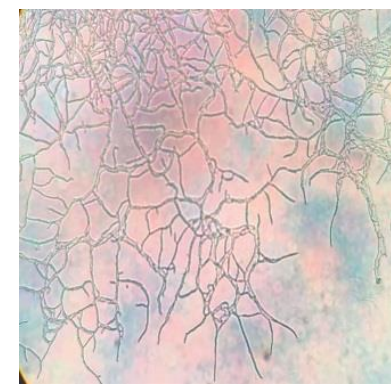

$\mathrm{AJ} 3$

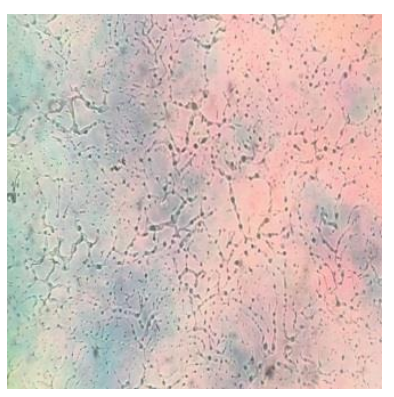

$\mathrm{AJ} 2$

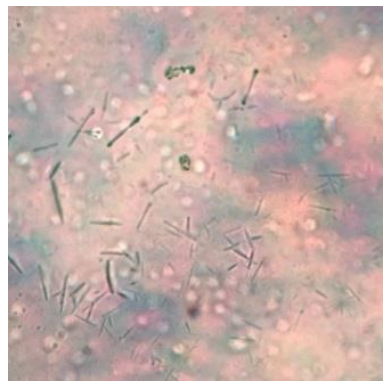

AJ4

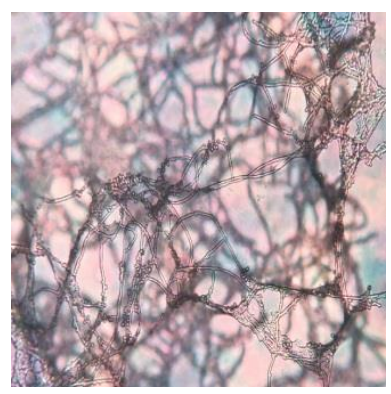

AJ5

Figure 4. Coverslip culture technique of the isolates $\mathrm{AJ} 1, \mathrm{AJ} 2, \mathrm{AJ} 3, \mathrm{AJ} 4$ and $\mathrm{AJ} 5$

The isolates AJ1, AJ2, AJ3, AJ4 and AJ5 were grown on different media to study their growth pattern. Accurate morphological characterization of the isolates producing catenulate spores is obviously dependent upon the use of a culture medium giving good sporulation. The growth rate also differed with respect to time. Starch casein agar medium (ISP4) was used as the growth media for all the five isolates. Glycerol asparagine agar (ISP5) and tyrosine asparagine agar (ISP7) resulted in dense growth of the isolates. This is in accordance with earlier reports [16]. Other morphological characteristics, such as colony appearance, aerial hyphae type, vegetative 
hyphal growth, fragmentation pattern of reproducing hyphae and asexual reproduction were detailed in Table 2 which indicates that they belong to the genus Actinomycetes.

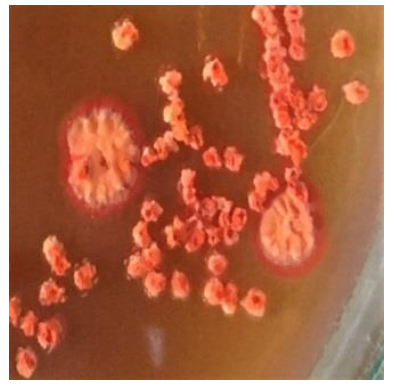

AJ1

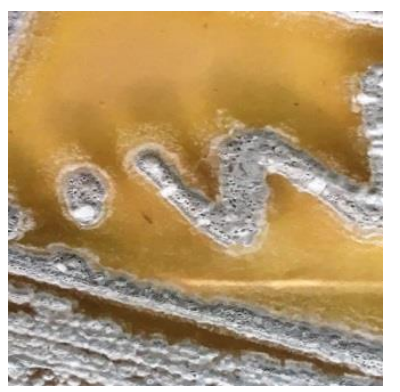

$\mathrm{AJ} 3$

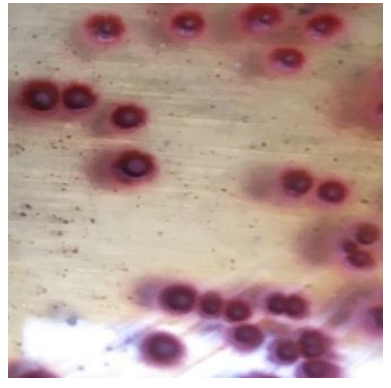

$\mathrm{AJ} 2$

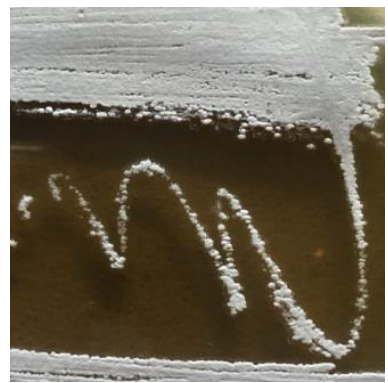

AJ4

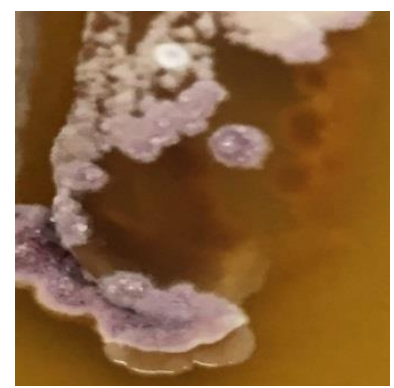

AJ5

Figure 5. Leathery orange spore mass colour of $\mathrm{AJ} 1$, dark pink spore mass colour of $\mathrm{AJ} 2$, leathery grey spore mass colour of $\mathrm{AJ} 3$, chalky white spore mass colour of AJ4, velvety pink spore mass colour of AJ5

The biochemical tests performed for the five isolates $\mathrm{AJ} 1, \mathrm{AJ} 2, \mathrm{AJ} 3, \mathrm{AJ} 4$ and $\mathrm{AJ} 5$ were enzymatic hydrolysis of starch, casein, gelatin and urea, acid production from different sugars, sulphur reduction test, sugar fermentation test, utilization of citrate, indole test, methyl red test, Voges-Proskauer test and catalase test were tabulated in Table 3 .

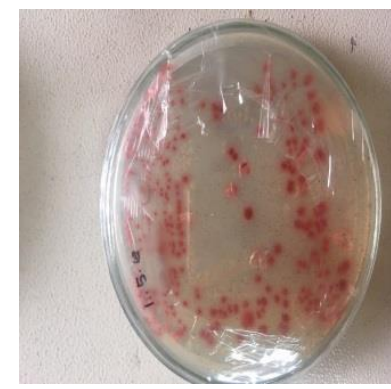

AJ1

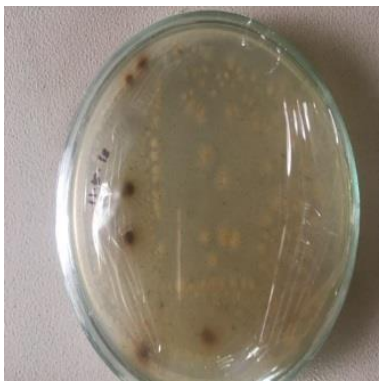

$\mathrm{AJ} 3$

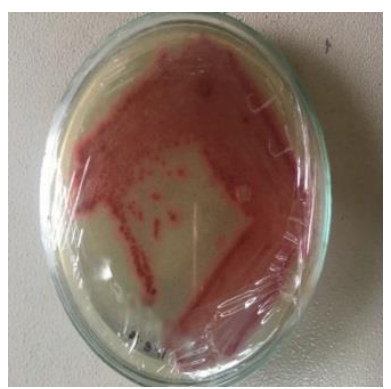

$\mathrm{AJ} 2$

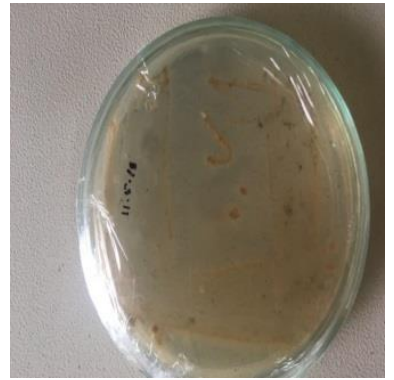

AJ4

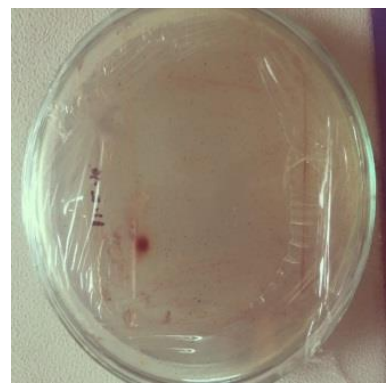

AJ5

Figure 6. Isolates showing different mycelial colour (colony reverse)

According to the description given in Bergey's Manual Part A (2001), all the five isolates $\mathrm{AJ} 1, \mathrm{AJ} 2, \mathrm{AJ} 3, \mathrm{AJ} 4$ and AJ5 were found to be positive for starch hydrolysis proving that they were able to degrade starch by producing the enzyme amylase. Hydrolysis of casein showed to be negative for all the five isolates as they did not produce an opaque zone around their growth. Isolate AJ1 was found to be negative for gelatin hydrolysis, followed by isolate AJ2, showed partial liquefaction, isolate $\mathrm{AJ} 3$ showed positive results, followed by isolate AJ4 that showed partial liquefaction of gelatin, and isolate AJ5 showed no liquefaction of gelatin. All the five isolates $\mathrm{AJ} 1, \mathrm{AJ} 2, \mathrm{AJ} 3$, $\mathrm{AJ} 4$, and AJ5 were found to be negative for urea hydrolysis. Actinomyces naeslundii genospecies 1 are one of the causative 
members of supragingival and subgingival dental plaque $[17,18]$ and showed suboptimal levels of urease activity $[19,20]$.

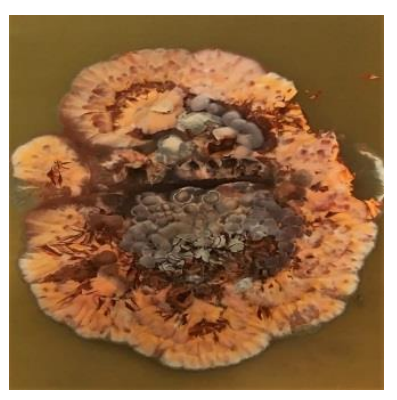

$\mathrm{AJ} 1$

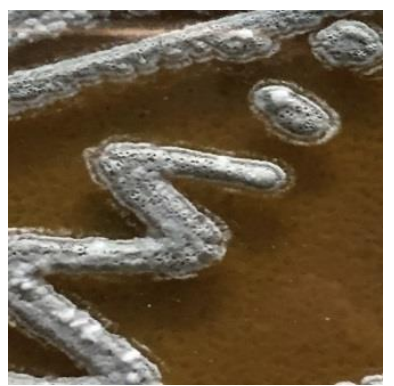

AJ3

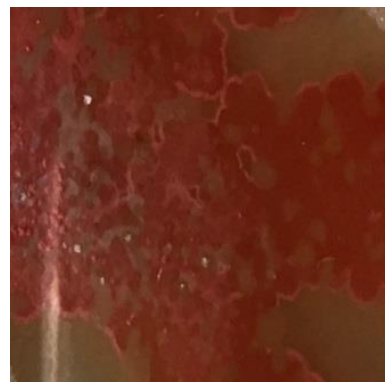

$\mathrm{AJ} 2$

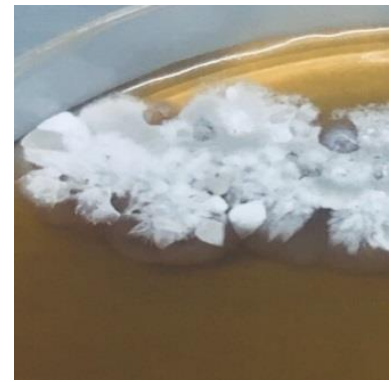

AJ4

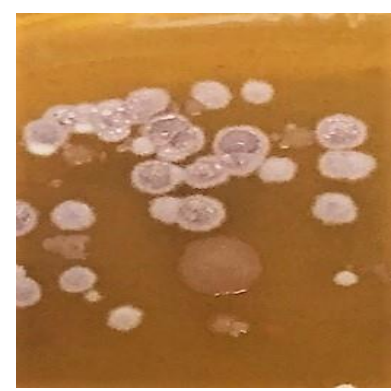

AJ5

Figure 7. Isolates $\mathrm{AJ} 1, \mathrm{AJ} 2, \mathrm{AJ} 3, \mathrm{AJ} 4$ and $\mathrm{AJ} 5$ showing concentric rings around the colonies

Table1. Cultural characters of the isolates AJ1, $\mathrm{AJ} 2, \mathrm{AJ} 3, \mathrm{AJ} 4$ and $\mathrm{AJ} 5$

\begin{tabular}{|c|c|c|c|}
\hline Isolates & $\begin{array}{c}\text { Aerial } \\
\text { spore mass }\end{array}$ & Texture & $\begin{array}{c}\text { Colony } \\
\text { reverse }\end{array}$ \\
\hline AJ1 & $\begin{array}{c}\text { Bright } \\
\text { orange }\end{array}$ & Flaky & Orange \\
\hline AJ2 & Dark pink & Leathery & Dark pink \\
\hline AJ3 & Light grey & Powdery & $\begin{array}{c}\text { Blackish } \\
\text { grey }\end{array}$ \\
\hline AJ4 & White & Chalky & $\begin{array}{c}\text { Creamish } \\
\text { yellow }\end{array}$ \\
\hline AJ5 & Pale pink & Velvety & Peach \\
\hline
\end{tabular}

Table 2. Growth rate of the isolates AJ1, AJ2, AJ3, AJ4 and AJ5

\begin{tabular}{|c|c|c|c|c|c|c|}
\hline \multirow{2}{*}{ Isolates } & \multicolumn{5}{|c|}{ Growth rate in different media } & \multirow{2}{*}{$\begin{array}{c}\text { Soluble } \\
\text { pigment }\end{array}$} \\
\cline { 2 - 6 } & SCA & OMA & GAA & TAA & YEMEA & \\
\hline AJ1 & ++ & +++ & +++ & +++ & ++ & NSP \\
\hline AJ2 & +++ & +++ & +++ & ++ & ++ & SP \\
\hline AJ3 & +++ & + & +++ & +++ & ++ & NSP \\
\hline AJ4 & ++ & +++ & +++ & +++ & +++ & NSP \\
\hline AJ5 & + & + & +++ & ++ & +++ & NSP \\
\hline
\end{tabular}

+++ - Excellent growth, ++ - Good growth, + - Moderate growth, NSP - No Soluble Pigment, SP - Soluble Pigment SCA - Starch casein agar, OMA - Oatmeal agar, GAA - Glycerol asparagine agar, TAA - Tyrosine asparagine agar, YEMEA - Yeas extract malt extract agar

Isolates $\mathrm{AJ} 1, \mathrm{AJ} 3$, and $\mathrm{AJ} 5$ showed positive results for citrate utilization, proving that the isolates were able to utilize citrate for its growth with the help of its enzyme citrase, which reduced the $\mathrm{pH}$ of the test slant, indicated by change in colour from green to blue, expressed by bromothymol blue indicator. The isolates $\mathrm{AJ} 2$ and $\mathrm{AJ} 4$, however, did not produce citrase hence no growth was found, showing negative result with no colour change. Isolates $\mathrm{AJ} 1, \mathrm{AJ} 2, \mathrm{AJ} 3, \mathrm{AJ} 4$, and $\mathrm{AJ} 5$ were found to produce bubbles of oxygen after addition of $\mathrm{H}_{2} \mathrm{O}_{2}$, releasing free oxygen bubbles, which showed catalase positive. Isolate AJ1 showed positive for indole test, which showed that isolate AJ1 was able to split amino acid tryptophan into the compound indole detected by a red coloured ring layer with the help of Kovacs reagent. The isolates $\mathrm{AJ} 1, \mathrm{AJ} 2, \mathrm{AJ} 3, \mathrm{AJ} 4$, and AJ5 were found to be methyl red positive, which indicates the fermentation of glucose, which produces large amounts of acids: formic, acetic, lactic, and succinic acid as final products. Isolates AJ1, $\mathrm{AJ} 2, \mathrm{AJ} 3$, and $\mathrm{AJ} 4$ produced both acid, thus lowering the $\mathrm{pH}$ of the test medium, detected by a colour change to yellow, and gas which has been trapped inside the Durham tubes placed in an inverted position, thereby utilizing the carbohydrate source, sucrose, and lactose. AJ2, AJ4, and AJ5 showed both acid and gas production by utilizing dextrose, which was indicated by a colour change in the test medium and air bubble was found trapped in the Durham tube. AJ1 and AJ3 showed only gas production for dextrose and isolate AJ5 for sucrose. 
Table 3. Biochemical characterization of the isolates AJ1, AJ2, AJ3, AJ4 and AJ5

\begin{tabular}{|c|c|c|c|c|c|c|c|c|c|c|c|c|c|}
\hline \multirow{2}{*}{ Isolates } & \multirow[t]{2}{*}{ Starch } & \multirow[t]{2}{*}{ Casein } & \multirow[t]{2}{*}{ Gelatin } & \multirow[t]{2}{*}{ Urea } & \multirow[t]{2}{*}{ Citrate } & \multirow[t]{2}{*}{ Catalase } & \multirow[t]{2}{*}{ Indole } & \multirow{2}{*}{$\begin{array}{l}\text { Methyl } \\
\text { red }\end{array}$} & \multirow{2}{*}{$\begin{array}{l}\text { Voges- } \\
\text { Proskauer }\end{array}$} & \multirow{2}{*}{$\begin{array}{l}\text { Hydrogen } \\
\text { Sulphide }\end{array}$} & \multicolumn{3}{|c|}{$\begin{array}{c}\text { Sugar } \\
\text { Fermentation }\end{array}$} \\
\hline & & & & & & & & & & & $\mathrm{S}$ & $\mathrm{L}$ & $\mathrm{D}$ \\
\hline AJ1 & + & - & NL & - & + & + & + & + & - & + & B & B & A \\
\hline AJ2 & + & - & PL & - & - & + & - & + & - & + & B & B & B \\
\hline AJ3 & + & - & $\mathrm{L}$ & - & + & + & - & + & - & + & $\mathrm{B}$ & $\mathrm{B}$ & $\mathrm{A}$ \\
\hline AJ4 & + & - & PL & - & - & + & - & + & - & + & $\mathrm{B}$ & $\mathrm{B}$ & $\mathrm{B}$ \\
\hline AJ5 & + & - & $\mathrm{L}$ & - & + & + & - & + & - & + & A & B & B \\
\hline
\end{tabular}

+ Positive, - Negative, L - liquefaction, PL - Partial liquefaction, NL - No liquefaction, ALK - Alkaline, A - acid, B - Both acid and gas production, $\mathrm{S}$ - Sucrose, L - Lactose, D - Dextrose

Simultaneously, all the five isolates showed positive for $\mathrm{H}_{2} \mathrm{~S}$, which indicated blackening butt due to precipitation of ferrous sulphide. The isolates $\mathrm{AJ} 1, \mathrm{AJ} 2, \mathrm{AJ} 3, \mathrm{AJ} 4$, and $\mathrm{AJ} 5$ showed negative for Voges-Proskauer test. On performing antimicrobial activity against Klebsiella, S.typhi, S.mutans, Enterobacter and E.coli, isolate AJ1 was found to show maximum zone of clearance of around $27 \mathrm{~mm}$ followed by $23 \mathrm{~mm}$ against S.typhi and with a minimum zone of clearance of $15 \mathrm{~mm}$ against Enterobacter. AJ3 isolate showed a moderate activity of $22 \mathrm{~mm}$ and isolate AJ5 with an activity of $19 \mathrm{~mm}$ against Klebsiella.

\section{DISCUSSION}

Heat-treated rhizosphere soil from Tulsi garden yielded 5 good strains of Actinomycetes which were subjected to morphological, cultural and biochemical characterization. Isolate AJ1 showed true mycelial structures with filamentous non-septate hyphae and extensive branching. Spore bearing hyphae falls under flexibillis structure. AJ2 isolate showed pseudo mycelium with filamentous septate branching. Spore bearing hyphae falls under retinaculum open loops. Isolate $\mathrm{AJ} 3$ showed true mycelium with non-septate hyphae and extensive branching. Spore bearing hyphae falls under biverticullus with no spirals. The isolate AJ4 showed simple true mycelium with non-septate non-sporing hyphae. The isolate AJ5 showed aerial mycelium with extensive branching, which had true mycelium and non-septate hyphae. The genus denotes aerobic Actinomycetes that are more inclined to form acid from carbohydrates, and form extensive monopodial and aerial mycelia with a DNA base composition denoting high GC content [21]. The isolate AJ1 showed flexibillis spore chain morphology, followed by the AJ2, which showed retinaculum open loops, followed by AJ3, which showed biverticullus with no spirals, AJ4 showed rectus structures and isolate AJ5 showed smooth conidia and monoverticillus with no spirals. Chromogenicity of aerial mycelium is considered an important character for grouping of actinomycetes [22]. Characterizations of Actinomycetes, such as spore morphology and spore surface ornamentation, are considered as valuable tools [23]. AJ1 showed orange concentric rings with raised grainy texture in the centre and shrinked edges. AJ2 showed dark pink matte colonies with raised faded shade in the centre and smooth edges. AJ3 showed grey puffed leathery colonies with raised powdery centres and granulated edges. AJ4 showed white chalky round colonies with raised smooth centres and split edges. Isolate AJ5 showed light pink colonies which had watery matte centres and smooth edges. Coverslip technique can be used to observe the spore bearing hyphae and spore chains under a light microscope [24, 25] as well as slide culture technique [26]. The isolates showed good growth and sporulation. Oatmeal agar (ISP3) was helpful for fast growth of the isolates. Yeast extract-malt extract agar (ISP2) resulted in the growth of aerial mycelium which must be due to the nutrients present in the medium. The media composition was found to enhance the appearance of aerial and substrate mycelium which coincides with earlier researchers [27, 28]. All the five isolates (AJ1, AJ2, AJ3, AJ4 and AJ5) showed 
positive results for starch hydrolysis, catalase test, methyl red and hydrogen sulphide test. These enzymes represent the largest groups of industrial enzymes [29], which are extensively utilized in food processing, medical, soaps and detergent industry.

The Actinomycetes are capable of degrading simple and complex substances present in their environment $[30,31]$ mentioning their composite substances and their genetic makeup [32] (Streptomyces genus) [33].

The antimicrobial activity of the isolates AJ1, $\mathrm{AJ} 2, \mathrm{AJ} 3, \mathrm{AJ} 4$, and AJ5 were recorded. Years ago there was a misinterpretation that identification of active secondary from Actinomycetes might reach an extreme restrainment. But with the recent advances in next generation sequencing [34] and bioinformatics tools available, genome models of actinomycetes [35, 36] are made available for references and their sequence analysis explore a number of rare Actinomycetes. Characterizations of new isolates pave way in exploring and identifying novel bioactive compounds with remarkable medicinal value. Only $3 \%$ of the antibacterial compounds produced by Streptomycetes have been reported [37]. Due to an increase in the alarming rate of multidrug resistant pathogens and novel phyto-pathogens, Actinomycetes has got its attention in isolating them from unexplored regions [38, 39].

The strains were therefore considered members of the Actinomycetes species. The scarcity of reports on industrially relevant enzymatic activities from the identified rare Actinomycetes indicated their potential for the production of various hydrolytic enzymes with a promising prospect for industrial application.

\section{CONCLUSION}

Five different Actinomycetes isolates found in the endogenous flora of soil resource were isolated with the isolation media - starch casein agar (SCA) and Actinomycetes isolation agar medium (AIA), showing smooth, leathery, matte colonies cultured by spread plate technique. Heat treatment of the garden soil sample aids the development of Actinomycetes populations inhibiting the growth of other organisms. Fertility of the soil also indicates the presence of Actinomycetes as they are known to be efficient in the production of soluble inorganic matter from the decomposition of chemicals compounds from organic forms. The isolates yields were different, although $\mathrm{AJ} 1, \mathrm{AJ} 3$ growth was dominant with better sporulation. Findings from the cultural, morphological and biochemical characteristics reveal that the isolates $\mathrm{AJ} 1, \mathrm{AJ} 2, \mathrm{AJ} 3, \mathrm{AJ} 4$ and $\mathrm{AJ} 5$ belong to the genus Actinomycetes.

\section{REFERENCES}

[1] D. Hillel, Soil in the Environment, Crucible of Terrestrial Life, Academic Press, New York, 2008.

[2] D.L. Dindal, Soil biology guide, John Wiley and Sons, New York, 1990.

[3] A. Absar, B. Shamsul, H. Rouf, A. Bhat, Actinomycetes benefaction role in soil and plant health, Microbial Pathogenesis 111(2017), 458-467.

[4] Y. Takahashi, S. Omura, Isolation of new actinomycete strains for the screening of new bioactive compounds, Journal of General Applied Microbiology 49(2003), 141-154.

[5] I. Ahmad, S. Ahmad, K.P. Rumbaugh, Antibacterial Drug Discovery to Combat MDR: Natural Compounds, Nanotechnology and Novel Synthetic Sources, Springer Nature, Singapore, 2019.

[6] M. Khanna, R. Lal, R. Solanki, Antimicrobial activities of actinomycetes from diverse ecological habitats in Delhi and its adjoining states, India, Journal of Microbiology 48(2011), 410-431.

[7] E. Kuester, S.T. Williams, Selection of media for Isolation of Streptomycetes, Nature 202(1964), 928-929. 
[8] E.B. Shirling, D. Gottlieb, Methods for Characterization of Streptomyces Species, International Journal of Systematic Bacteriology 16(1966), 313340.

[9] J.G. Cappuccino, N. Sherman, Microbiology: A Laboratory Manual, $7^{\text {th }}$ Edition, Benjamin Cummings, United States, 2004.

[10] V. Duraipandiyan, A.H. Sasi, S. Ignacimuthu, Antimicrobial properties of actinomycetes from the soil of Himalaya, Journal of Medical Mycology 20(2010), 15-20.

[11] H. Nonomura, Key for classification and identification of 458 species of the Streptomycetes included in ISP, Journal of Fermentation Technology 52(1974), 78-92.

[12] R.K. Manhas, S. Bala, Thermostable Glucose Isomerase Production by Some Bacteria and Streptomyces, Indian Journal of Microbiology 44(2004) 2, 129-132.

[13] M.V. Srinivasan, A. Laughlin, Predictive coding: A fresh view of inhibition in the retina, Proceedings of the Royal Society of London B 216(1982), 427-459.

[14] E.B. Shirling, D. Gottlieb, Methods for characterization of Streptomyces species, International Journal of Systematic Bacteriology 16(1966) 3, 313-340.

[15] E.A. Barka, P. Vatsa, L. Sanchez, N.G. Vaillant, C. Jacquard, H.P. Klenk, C. Clément, Y. Ouhdouch, G.P. Wezel, Taxonomy, Physiology, and Natural Products of Actinobacteria, American Society for Microbiology, Microbiology and Molecular Biology Reviews 80(2016), 1-43.

[16] G.H. Bowden, J.M. Hardie, G.L. Slack, Microbial variation in approximal dental plaque, Caries Research 9(1975), 253277.

[17] J.V. Houte, J. Lopman, R. Kent, The predominant cultivable flora of sound and carious human root surface, Journal of Dental Research 73(1994), 17271734.

[18] N.O. Salako, I. Kleinherg, Incidence of selected ureolytic bacteria in human dental plaque from sites with differing salivary access, Archives of Oral Biology 34(1989), 787-791.

[19] R.L. Wijeyweera, I. Kleinherg, Arginolytic and ureolytic activities of pure cultures of human oral bacteria and their effects on the $\mathrm{pH}$ response of salivary sediment plaque in vitro, Archives of Oral Biology 34(1989), 4553.

[20] E.G. Mai, M. Reiner, R.M. Kroppenstedt, F.K. Wendisch, H.J. Kutzner, Morphological and Biochemical Characterization and Emended Descriptions of Thermophilic Actinomycetes Species, Systematic and Applied Microbiology 9(1985), 97-109.

[21] T.C. Pridham, H.D. Tresner, Streptomyces, Bergey's Manual of Determinative Bacteriology, $8^{\text {th }}$ Edition, Williams and Wilkins, Baltimore, 1974.

[22] H.D. Tresner, Compendium of Actinobacteria from Dr. Joachim M. Wink, University of Braunschweig, International Journal of Systematic Bacteriology 30(1961), 372.

[23] M. Arifuzzaman, M.R. Khatun, H. Rahman, Isolation and screening of actinomycetes from Sundarbans soil for antibacterial activity, African Journal of Biotechnology 9(2010) 29, 4615-4619.

[24] M.R. Khan, M.L. Saha, Bacteria and Actinomycetes growing on floppy and compact discs under ambient conditions, Bangladesh Journal of Botany 37(2008) 1, 7-14.

[25] A. Kavitha, M. Vijayalakshmi, Isolation and characterization of actinomycetes from marine soil samples, Journal of Applied Sciences Research 3(2007) 12, 2026-2029.

[26] K. Okami, Y.H. Umezawa, Ablastmycin, a newanti-piricularia antibiotic, Antibiotics 21(1968), 37-43.

[27] A.S. Marroquin, Constancy of Characteristics in the Streptomycetes, Journal of Bacteriology 83(1962) 6, 1183-1192.

[28] O. Kirk, T.V. Borchert, C.C. Fuglsang, Industrial enzyme applications, Current 
Opinion in Biotechnology 13(2002), 345-351.

[29] A.J. McCarthy, T.W. Stanley, Actinomycetes as Agents of Biodegradation in the Environment - a Review, Gene 115(1992) 1-2, 189-192.

[30] M. Tuomela, M. Vikman, A. Hatakka, M. Itävaara, Biodegradation of lignin in a compost environment: a review, Bioresource Technology 72(2000) 2, 169-183.

[31] S.D. Bentley, K.F. Chater, A.M. Cerdeño-Tárraga, G.L. Challis, N.R. Thomson, K.D. James, D.E. Harris, Complete genome sequence of the model actinomycete Streptomyces coelicolor A3, Nature 417(2002) 6885, 141-147.

[32] K.J. Narayana, P. Prabhakar, M. Vijayalakshmi, Y. Venkateswarlu, P.S. Krishna, Activity of phenylpropionic acid isolated from a terrestrial Streptomycetes, Polish Journal of Microbiology 56(2007) 3, 191-197.

[33] D.M. Sylvia, J.J. Fuhrmann, P.G. Hartel, D.A. Zuberer, Principles and applications of soil microbiology, $2^{\text {nd }}$ Edition, Pearson Prentice Hall, Upper Saddle River, New Jersey, 2004.

[34] D.W. Udwary, L. Zeigler R.N. Asolkar, V. Singan, A. Lapidus, W. Fenical, Genome sequencing reveals complex secondary metabolome in the marine actinomycete Salinispora tropica, Proceedings of the National Academy of Science 104(2007), 10376-10381.

[35] H. Ikeda, J. Ishikawa, A. Hanamoto, M. Shinose, H. Kikuchi, T. Shiba, Complete genome sequence and comparative analysis of the industrial microorganism Streptomyces avermitilis, Nature Biotechnology 21(2003) 5, 526-531.

[36] Y. Ohnishi, J. Ishikawa, H. Hara, H. Suzuki, M. Ikenoya, H. Ikeda, Genome sequence of the streptomycin-producing microorganism Streptomyces griseus IFO 13350, Journal of Bacteriology 190(2008), 4050-4060.

[37] M.G. Watve, R. Tickoo, M.M. Jog, B.D. Bhole, How many antibiotics are produced by the genus Streptomyces?,
Archives of Microbiology 176(2001), 386-390.

[38] A.B. Espinosa, K.C. Freel, P.R. Jensen, I.E. Soria-Mercado, Marine actinobacteria from the Gulf of California: diversity, abundance and secondary metabolite biosynthetic potential, Antonie Van Leeuwenhoek 103(2013), 809-819.

[39] N. Nilar, P.J. Sidebottom, B.K. Carte, M.S. Butler, Three new pyridoacridine type alkaloids from a Singaporean ascidian, Journal of Natural Products 65(2002), 1198-1200. 